MATTERS ARISING

\section{Incidence of RA in people with persistently raised $R F$}

A criticism of the study reported in the Annals $^{1}$ is that age was not taken into account in the evaluation of the probability of development of rheumatoid arthritis (RA) among symptom free subjects with persistently raised rheumatoid factor (RF). The prevalence of $\mathrm{RF}$ can be as high as $14.1 \%$ in apparently healthy people aged 67-95 (mean age 81$).{ }^{2} \mathrm{RF}$ is also 3.5 times more common in healthy elderly subjects (aged $>65$ ) than in their younger counterparts. ${ }^{3}$ All these factors may alter the natural history of arthritis in elderly patients who have RF either in good health or in a non-arthritic presentation of RA.

The latter is exemplified by a patient admitted at the age of 76 with symptomatic, as well as echocardiographically validated rheumatoid pericarditis in the absence of arthritis Rheumatoid arthritis latex fixation test (RA LFT) was positive with a titre of $1 / 160$, antinuclear factor (ANF) titre was $1 / 250$, and signs of active inflammatory disease included a platelet count of $750 \times 10^{\circ} / 1$, and an erythrocyte sedimentation rate (ESR) of $98 \mathrm{~mm} / 1 \mathrm{st} \mathrm{h}$ (Westergren). Arthralgia of the hands and wrists developed for the first time two years later (when she was no longer taking steroids), with a subsequent RA LFT titre of $1 / 80$ and an ANF titre of $1 / 320$ about four months after the onset of arthralgia. Radiography showed narrowing of the joint spaces of the hands 12 months later, but there were as yet no erosions at this stage. Erosions were seen in March 1992, approximately two and a half years after the onset of arthralgia, when the RA LFT titre was $1 / 160$, ANF titre $1 / 160$, platelet coun $421 \times 10^{\circ} / 1$, ESR $18 \mathrm{~mm} / 1 \mathrm{st} \mathrm{h}$. At her most recent attendance, on 2 February 2000, she was still very active, having continued to receive prednisolone (maximum dose $5 \mathrm{mg} / \mathrm{d}$ ) continuously since 1989 . Her only complaint was a little pain in the left thenar eminence and painful heels. RF was now $768 \mathrm{IU} / \mathrm{ml}$, ANF titre $1 / 320$, platelet count $340 \times 10^{9} / 1$, ESR $42 \mathrm{~mm} / 1 \mathrm{st} \mathrm{h}$. Antibodies against double stranded DNA had not been reported at any stage.

\section{COMMENT}

This case shows a remarkable dissociation between arthritic symptoms and levels of RF, perhaps signifying that when the immune status is altered in old age, ${ }^{2}$ the relation between $\mathrm{RF}$ and the natural history of RA might be less clear than it is in younger people.

O M P JOLOBE

Department of Medicine for the Elderly, Tameside General Hospital, Fountain Street

Ashton under Lyne OL6 9RW, UK

1 Halldórsdóttir HD, Jónsson T, Thorsteinsson J, Valdimarsson $\mathrm{H}$. A prospective study on the incidence of rheumatoid arthritis among people with persistent increase of rheumatoid factor. Ann Rheum Dis 2000;59:149-51.

2 Manoussakis MN, Tzioufas AG, Silis MP, Pange PJ, Goudevenos J, Moutsopoulos HM High prevalence of anti-cardiolipin and other autoantibodies in a healthy elderly popu
Clin Exp Immunol 1987;69:557-65.
3 Goodwin JS, Searles RP, Tung KSK. Immunothy elderly population. Clin Exp Immunol 1982;48:403-10.

\section{Author's reply}

It is certainly well documented that the incidence of raised rheumatoid factor (RF) increases with age. However, we are not aware of any study of different RF isotypes in this context, but our own unpublished observation indicates that it is mainly $\operatorname{IgM} R F$ that tends to increase in symptom free elderly people.

However, increased incidence of raised RF in elderly people is not relevant to the findings that we published recently in the Annals. ${ }^{1}$ We simply observed increased prevalence and incidence of rheumatoid arthritis (RA) in elderly subjects who had one or more $\mathrm{RF}$ isotypes persistently raised, usually $\mathrm{IgM}$ and $\operatorname{IgA}$, compared with those with a transient increase in RF or persistent increase in only one RF isotype. There was no significant age difference between these three groups of subjects studied.

Dr Jolobe's case history simply confirms what has already been often reported previously that an increase of RF often precedes clinical manifestation of RA. ${ }^{2}$ It would have been interesting to know about the RF isotype pattern of his patient. We have noted that the pulmonary manifestation of RA is strongly associated with raised $\operatorname{IgA~RF}$. $^{3}$

HELGI VALDIMARSSON Department of Immunology, National University Hospital, Landspitalinn, 101 Reykjavik, Iceland

1 Halldórsdóttir HD, Jónsson T, Thorsteinsson J, Valdimarsson $\mathrm{H}$. A prospective study on the incidence of rheumatoid arthritis among people with persistent increase of rheumatoid factor. Ann Rheum Dis 2000;59:149-51.

2 Jónsson Th, Thorsteinsson J, Kolbeinsson K, Jónsdóttir E, Sigfússon N, Valdimarsson $\mathrm{H}$. Population study of the importance of rheumatoid factor isotypes in adults. Ann Rheum Dis 1992;51:863-8.

3 Lúdvíksson BR, Jónsson T, Erlendsson K, Sigfússon A. Disease manifestations in patients with isolated elevation of IgA rheumatoid factor. Scand J Rheumatol 1992;21:1-4.

\section{LETTERS TO THE EDITOR \\ The HLA-B ${ }^{\star 2} 209$ subtype in a patient with undifferentiated spondarthritis}

In 1998, in this journal, we reported the cases of two B27 positive patients with undifferentiated spondyloarthropathy (uSpA) and showing dactylitis also affecting the synovial sheaths in the palm of the hand. ${ }^{1}$ Neither patient had axial disease but showed peripheral manifestations of spondyloarthropathy (SpA), such as peripheral arthritis, peripheral enthesitis, and dactylitis.
Recently, one of our two patients (No 2) was subtyped and found to be $B^{\star} 2709$ positive. As far as we know this subtype has never been found in patients with $\mathrm{SpA}$

DNA typing of HLA class I alleles was performed using a DNA sample prepared from peripheral blood lymphocytes by the salting out procedure. $^{2}$ The class 1 ABC SSP UNITRAY low resolution kit (Pel-Freez) was used. The primer sets amplify all alleles described by the International Nomenclature Committee of WHO in $1995^{3}$ and in $1997 .{ }^{4}$ Polymerase chain reaction amplification with sequence-specific primers (PCR-SSP) was used. A control primer pair was present to verify the integrity of the PCR reaction. Molecular typing of B27 variants was carried out by a PCR-SSP technique with a DYNAL HLA-B27 kit (DYNAL AS, Oslo, Norway), which identifies all the phenotypically different HLA-B27 alleles, $B^{\star} 2701-11$, recognised by the HLA Nomenclature Committee in 1973. ${ }^{3}$ The typing results for our patients were: HLA-A ${ }^{\star} 0101-02$, $\star 3201-02$; HLA$\mathrm{B}^{\star} 0801$ ， ${ }^{\star} 2709$; HLA-C ${ }^{\star} 0102-03,{ }^{\star} 0701-$ 07 .

To confirm these results HLA-B locus sequence based typing was performed. A unique DNA amplification, encompassing exon 1 to intron 3, and four fluorescent sequencing reactions, covering exon 2 and 3 , were used. ${ }^{5}$ Two intronic amplification primers generated a $1 \mathrm{~kb}$ length product useful for direct sequencing. For complete subtyping of the allelic variants PCR-SSP was used. Cycle sequencing reactions allowed the incorporation of fluorescently labelled dideoxy terminators for detection on a DNA automated sequencer (ABI PRISM 377, Perkin Elmer). Data processing and allele assignment were performed automatically with specific analysis software that compares the sequencing results against a sequence library and provides individual allele assignment for each sequence. The HLA-B class 1 high resolution typing of our sample was HLA-B ${ }^{\star} 0801 / 2709$ in agreement with the low resolution typing performed by PCR-SSP.

SpA has a strong association with the HLA-B27 molecule. Studies in humans and transgenic rodents suggest a direct involvement of HLA-B27 in the pathogenesis of the disease. Thirteen subtypes of HLA-B27 (B* 01-13) have been described, differing from each other by one or more amino acid changes, mainly in the peptide-binding site. ${ }^{67}$ Of these $B^{\star} 2701,02,03,04,05,07,08$, and 10 are associated with ankylosing spondylitis (AS). $\mathrm{B}^{\star} 2711-13$ are rare, which has precluded assessing their putative association with AS. B ${ }^{\star} 2706$ is not associated with AS in South East Asia. However some $B^{\star} 2706$ positive patients with AS have been reported in China. ${ }^{8}$ It has been suggested that the $B^{\star} 2706$ might protect against SpA. Recently, a study on families in which both $\mathrm{B}^{\star} 2704$ and $B \star 2706$ occurred has suggested that $B^{\star} 2706$, although not associated with $\mathrm{SpA}$, does not protect against $\mathrm{SpA}$.

$B \star 2709$ has been found in Sardinia and in continental Italy, where the frequency of HLA-B27 in the general population is around $2 \%$. B 2709 accounts for $25 \%$ of HLA-B27 subtypes in Sardinia and 3\% in continental Italy. ${ }^{10}$ D'Amato and coworkers have tested 35 Sardinian patients with AS and 40 Sardinian B27 positive healthy subjects by genomic typing. ${ }^{10}$ None of the patients with AS were found to be $B^{\star} 2709$ positive, in contrast with $25 \%$ among the healthy controls. The authors suggested that $B^{\star} 2709$ is not 
associated with AS. $B^{\star} 2709$ differs from $\mathrm{B}^{\star} 2705$ by a single substitution (His $v \mathrm{Asp}$ ) at position 116, which is located in the $\mathrm{F}$ pocket of the peptide-binding site. In the opinion of D'Amato and his colleagues the substitution at position 116 might exclude the acceptance of arthrogenic peptide from the $\mathrm{B}^{\star} 2709$.

Our patient was born in the south of Italy, she is B27 positive, and has uSpA with an erosive and disabling peripheral arthritis. Our case, also, suggests that the $B^{\star} 2709$ might be associated with $\mathrm{SpA}$ and that the negative association found in Sardinian patients with $\mathrm{AS}^{10}$ should be confirmed in other studies. These should include the full spectrum of SpA and not be limited to AS.

IGNAZIO OLIVIERI ANGELA PADULA GIOVANNI CIANCIO Rheumatic Disease Unit of the S Carlo Hospital,

Potenza, Italy

LEDA MORO

ELISABETTA DURANTE

Tissue Typing Laboratory of the Blood Bank of "Ca" Foncello" Hospital,

Treviso, Italy

CARLO GAUDIANO

SANTA MASCIANDARO

HLA Typing Service of Matera Hospital, Matera, Italy

SARAH POZZI

G B FERRARA

National Cancer Institute of the Advanced Biotechnology Centre,

Genova, Italy

Correspondence to: Dr Ignazio Olivieri, Servizio di Reumatologia, Ospedale S Carlo, Contrada Macchia, Romana, 85100 Potenza, Italy

Email: ignazioolivieri@tiscalinet.it

1 Padula A, Olivieri I, Barozzi L, Salvarani C, Cantini F, De Matteis M, et al. Dactylitis also involving the synovial sheaths in the palm of the hand: two more cases studied by magnetic resonance imaging. Ann Rheum Dis 1998;57:61-2.

2 Miller SA, Dykes DD, Polesky HF. A simple salting out procedure for extracting DNA from human nucleated cells. Nucleic Acids Res 1988;16:1215-18.

3 Brodmer JG, Marsh S, Ekkehard DA. Nomenclature for factors of HLA system. Tissue Antigens 1995;46:1-18.

4 Nomenclature for factors of HLA system, update March 1997. Tissue Antigens 1997;49: 675-6.

5 Pozzi S, Longo A, Ferrara GB. HLA-B locus sequence-based typing. Tissue Antigens 1999; 53:275-81

6 López de Castro JA. The pathogenetic role of HLA-B27 in chronic arthritis. Curr Opin Immunol 1998;10:59-66.

7 Gonzàlez S, Martinez-Borra J, López-Larrea C. Immunogenetics, HLA-B27 and spondyloarthropathies. Curr Opin Rheumatol 1999;11: thropathies.

8 Gonzales-Roces S, Alvares MV, Gonzales S, Dieys A, Makni H, Woodfield DG, et al. HLAB27 polymorphism and worldwide susceptibility to ankylosing spondylitis. Tissue Antigens 1997;49:116-23.

9 Sudarsono D, Hadi S, Mardjuadi A, Nasution AR, Dekker-Sayes A, Breur-Vrisendorp BS, et al. Evidence that HLA-B ${ }^{\star} 2706$ is not protective against spondyloarthopathy. J Rheumato 1999;26:1934-6.

10 D'Amato M, Fiorillo MT, Carcassi A, Mathieu A, Zuccarelli A, Bitti PP, et al. Relevance of residue 116 of HLA-B27 in determining susceptibility to ankylosing spondylitis. Eur J Immunol 1995;25:3199-201.

\section{Y chromosome microchimerism in rheumatic autoimmune disease}

It is well known that some features of chronic graft-versus-host disease (GVHD) resemble those of other rheumatic autoimmune diseases, such as systemic sclerosis (SSc), Sjögren's syndrome (SS), and primary biliary cirrhosis (PBC). Furthermore, the development of systemic lupus erythematosus (SLE)-like diseases has been seen in murine models of GVHD. ${ }^{1}$ The pathogenesis of rheumatic autoimmune diseases is still unknown. One possibility that has been suggested is that these diseases are associated with pregnancy because of their strong female predilection and, especially in SSc, a peak incidence after parturition. In 1996 Bianchi et al reported that fetal cells could survive in the maternal circulation for up to 27 years after parturition, a phenomenon termed fetal microchimerism. ${ }^{2}$ These observations led the hypothesis that persistent fetal cells in the maternal circulation could mediate a graftversus-host reaction, resulting in autoimmune disease.

Nelson et al have previously carried out a quantitative assay for male DNA in women with SSc and normal women who had delivered at least one son. ${ }^{3}$ They indicated that the mean number of male cell DNA equivalents among controls was 0.38 cells $/ 16 \mathrm{ml}$ whole blood and 11.1 among patients with SSc. In addition, Artlett et al have shown Y chromosome-specific sequences in the DNA extracted from peripheral blood in 32 of 69 women with SSc $(46 \%)$ as compared with 1 of 25 normal women (4\%). ${ }^{4}$ They also reported that those allo-cells were $\mathrm{T}$ lymphocytes and infiltrated lesional skin. These findings support the hypothesis that fetal microchimerism may contribute to the pathogenesis of SSc. However, this is still controversial because Murata et al have recently reported that there is no significant difference in the presence of fetal DNA in peripheral blood between Japanese patients with SSc and healthy women with nonquantitative assay. ${ }^{5}$ Here we report further studies of fetal microchimerism in SSc, SLE, and SS.

We assayed for a specific $\mathrm{Y}$ chromosome sequence in the DNA extracted from peripheral blood by a nested polymerase chain reaction (PCR) in 20 patients with SSc, 21 patients with SLE, 18 patients with SS, and 41 healthy volunteers. All patients and healthy volunteers were Asian-Japanese women who had delivered at least one son. The nested PCR was done using the primers $\mathrm{Y} 1-1, \mathrm{Y} 1-2, \mathrm{Y} 1-3$, and $\mathrm{Y} 1-4$, which are specific for a part of the $\mathrm{Y}$ chromosome sequence, DYZ1, as described previously. ${ }^{4}{ }^{6}$ The identity of the detected PCR product was confirmed by nucleotide sequencing. The results from healthy volunteers and test

Table 1 Patients'characteristics

\begin{tabular}{lllll}
\hline & $S S c$ & $S L E$ & $S S \ddagger$ & Healthy controls \\
\hline Patients (n) & 20 & 21 & 18 & 41 \\
Age (years, mean (range)) & $56.1(44-74)$ & $50.2(34-82)$ & $54.8(27-74)$ & $53.2(39-59)$ \\
Duration of illness (years, mean (range)) & $10.2(1-26)$ & $11.9(1-24)$ & $8.7(1-19)$ & $8(20)$ \\
DYZ1 positive (No (\%)) & $10^{\star}(50)$ & $0 \dagger(0)$ & $6(33)$ & $8(20)$ \\
\hline
\end{tabular}

${ }^{\star} \mathrm{p}=0.017$, systemic sclerosis $(\mathrm{SSc}) v$ healthy volunteers.

$t \mathrm{p}=0.028$, healthy volunteers and systemic lupus erythematosus (SLE).

$\ddagger S S=$ Sjögren's syndrome.

Table 2 Comparison of clinical findings of DYZ1 positive and negative systemic sclerosis groups

\begin{tabular}{llll}
\hline & \multicolumn{2}{c}{ DYZ1 } \\
\cline { 2 - 4 } & $\begin{array}{l}\text { Positive } \\
(n=10)\end{array}$ & $\begin{array}{l}\text { Negative } \\
(n=10)\end{array}$ & $\begin{array}{l}\text { Total } \\
(n=20)\end{array}$ \\
\hline Barnett's type, & & & \\
I & 3 & 4 & 7 \\
II & 3 & 5 & 8 \\
III & 4 & 1 & 5 \\
Autoantibodies & & & \\
Antinuclear factor & 10 & 8 & 18 \\
Topoisomerase I & 4 & 1 & 5 \\
Centromere (PBC & $3(3)$ & $8(0)$ & $11(3)$ \\
RNP & 4 & 0 & 4 \\
SS-A(Ro) & 2 & 3 & 5 \\
SS-B(La) & 0 & 0 & 0 \\
RA & 3 & 1 & 4 \\
ssDNA & 2 & 1 & 3 \\
Mitochondria & 2 & 0 & 2 \\
Smooth muscle & 1 & 0 & 1 \\
\hline
\end{tabular}

${ }^{\star} \mathrm{PBC}=$ primary biliary cirrhosis.

groups were compared by Fisher's extract probability test.

Y chromosome-specific DNA was detected in 10 of the 20 patients with SSc (50\%), eight of 41 healthy volunteers $(20 \%, p=0.017)$, and six of 18 patients with SS (33\%). No Y chromosome-specific DNA was detected in any of the patients with SLE (table 1). The DYZ1 was most commonly found in Barnett's type III (four of five). The DYZ1 positive patients with SSc also had a variety of antibodies including anti-RNP, antimitochondrial, and anti-smooth muscle antibodies that may reflect polyclonal activation of immune cells. Anticentromere antibodies were detected more commonly in the DYZ1 negative group (eight of 10). All three patients with SSc who had PBC were DYZ1 positive and had anticentromere antibodies (table 2).

Our data confirm that male DNA is found more commonly in women with SSc than in normal women. Interestingly, DYZ1 was not detected in patients with SLE and there was no significant difference between patients with SS and healthy volunteers. These data suggest that fetal microchimerism may be a phenomenon which is strongly associated with the pathogenicity of SSc and not with the related autoimmune diseases, SLE and SS.

YUKO MIYASHITA MASASHI ONO MARIKO ONO HIROAKI UEKI Department of Dermatology, Kawasaki Medical School, 577 Matsushima Kurashiki 701-0192, Japan

KAZUHIRO KURASAWA Department of Internal Medicine II, Chib a University of Medicine, Chiba 260-0856, Japan 
Correspondence to: Dr Yuko Miyashita

Email: yukomiya@med.kawasaki-m.ac.jp

1 van Dam AP, Meilof JF, van den Brink HG, Smeenk RJT. Fine specificities of anti-nuclear
antibodies in murine models of graft-versusantibodies in murine models of graft-versus2 Bianch DW, Zickwolf GK, Weil GJ, Sylvester S, Bianch DW, Zickwolf GK, Weil GJ, Sylvester S,
DeMaria MA. Male fetal progenitor cells DeMaria MA. Male fetal progenitor cells
persist in maternal blood for as long as 27 years persist in maternal blood for as long as 27 years 93:705-8.

3 Nelson JL, Furst DE, Maloney S, Gooley T Evans PC, Smith A, et al. Microchimerism and HLA-compatible relationships of pregnancy in scleroderma. Lancet 1998;351:559-62.

4 Artlett CM, Smith JB, Jimenz SA. Identification of fetal DNA and cells in skin lesions from women with systemic sclerosis. N Engl J Med 1998;338:1186-91.

5 Murata H, Nakauchi H, Sumida T. Microchimerism in Japanese women patients with merism in Japanese women patients

6 Patri S, Daheron L, Kitzis A, Chomel JC. Patri S, Daheron L, Kitzis A, Chomel JC.
Evaluation of bone marrow transplantation Evaluation of bone marrow transplantation
efficiency by competitive PCR on Y sequences PCR Methods and Applications 1994;3 361-4.

\section{Marker of erosive progression in RA}

Urokinase plasminogen activator (uPA) catalyses the formation of the proteolytic enzyme plasmin, which plays a part in tissue degradation and remodelling, ${ }^{1}$ and seems to have an important role in the erosive growth of pannus in rheumatoid arthritis (RA). ${ }^{2}$ The action of uPA is localised and intensified by a cell bound receptor (uPAR), ${ }^{3}$ expressed by some malignant cells and some inflammatory cell types, including activated synoviocytes in the marginal zone between pannus and cartilage in RA synovial tissue. ${ }^{4}$

The uPAR may become cleaved at the cell surface bound anchor, forming a free soluble receptor (suPAR) which is detectable in steady, low concentrations in healthy controls, but with raised concentrations in patients with disseminated malignant disease. $^{5}$

Recently, in a cross sectional study, we found increased concentrations of suPAR in plasma of patients with RA compared with controls and patients with other types of inflammatory rheumatic disorders. ${ }^{6}$ This finding raises the question, whether suPAR might be an easily accessible plasma marker of erosive activity in the synovial joint space in RA.

In a pilot study we followed up outpatients with RA to evaluate the relation between suPAR and disease activity. Plasma suPAR was measured and other clinical and paraclinical variables of disease activity determined in these patients on two or more occasions during a 12 month period. The present study included all patients $(n=16)$ for whom comparable radiographs of the wrists and hands were obtainable, and also, when relevant, other symptomatic joints, taken before and after the period of suPAR measurements. The $x$ ray films of participating patients were read independently by a radiologist unaware of the patient's clinical status and suPAR values. An enzyme linked immunoabsorbent assay (ELISA) was used to measure suPAR in plasma, as previously described. $^{56}$

Table 1 Period average values of corresponding paraclinical and clinical variables of 16 patients with rheumatoid arthritis followed up prospectively and subsequently divided into two groups with or without progressive erosive changes on radiographs. Values are medians with range

\begin{tabular}{lll}
\hline & Erosive progression $(n=5)$ & No erosive progression $(n=11)$ \\
\hline suPAR† $(\mu \mathrm{g} / \mathrm{l})$ & $1.51(0.93-2.73)^{\star}$ & $1.03(0.56-2.09)^{\star}$ \\
$\mathrm{CRP}+(\mathrm{mg} / \mathrm{l})$ & $11.4(6.1-30.1)$ & $11.0(4.2-29.5)$ \\
ESR† $(\mathrm{mm} / \mathrm{st} \mathrm{h})$ & $24(15-24)$ & $16(7-58)$ \\
Tender joints (of 28) & $6(3-20)$ & $4(0-17)$ \\
Swollen joints (of 28) & $4(1-8)$ & $2(0-10)$ \\
\hline
\end{tabular}

${ }^{\star} \mathrm{p}<0.05$, non-parametric Mann-Whitney test.

tsuPAR = soluble urokinase plasminogen activator in plasma; CRP $=\mathrm{C}$ reactive protein; ESR = erythrocyte sedimentation rate.

The study group comprised 11 women and five men with a median age of 53.5 years (range 25-80) and a median disease duration of 57 months (range 5-360). Fifteen patients were rheumatoid factor positive and $10 \mathrm{had}$ bony erosions on prestudy radiographs. Antirheumatic treatment included methotrexate (11 patients), hydroxychloroquine (two), sulfasalazine (one), and low dose steroids (eight). Clinical evaluation and measurement of suPAR, erythrocyte sedimentation rate (ESR), and $C$ reactive protein (CRP) were done a median number of three times, and the time interval between radiographs was a median of 22 months.

Table 1 shows the results of the study. We found significantly higher suPAR concentrations $(p<0.05)$ in plasma from those patients with RA whose $x$ ray findings showed disease progression than in the patients who had no radiographic signs of progression, but the differences in ESR, CRP, and clinical variables were not significantly different.

This study was a pilot study in a clinical setting and conclusions must be drawn cautiously. The main problems, apart from the small number of patients, are, firstly, that in some of the patients prestudy radiographs were one to two years old. However, this would tend to diminish the differences found between the erosive progressive and nonerosive progressive groups as patients in remission, or with low activity in the study period, could be classified as progressive due to previous activity. Secondly, another possible bias, tending to increase the difference in suPAR between the two groups in this study, is that patients with high clinical activity would probably have had more extensive $x$ ray examinations, increasing the chance of finding new erosions. We did not, however, find a difference in the number of radiographically investigated joints between our two groups of patients.

In conclusion, we find that this study indicates that plasma suPAR may be an easily accessible plasma marker of erosive progression in RA, and further studies on the subject are warranted.

OLE SLOT Departments of Rheumatology, Copenhagen County Hospital Gentofte and Naestved Central Hospital, Denmark

NILS BRÜNNER ROSS W STEPHENS The Finsen Laboratorium, Copenhagen University Hospital Rigshospitalet, Denmark
Correspondence to: Dr Ole Slot, Department of Rheumatology, Naestved Central Hospital, DK4700 Naestved, Denmark

1 Danø K, Behrent N, Brünner N, Ellis V, Ploug $\mathrm{M}$, Pyke C. The urokinase receptor. Protein structure and role in plasminogen activation and cancer invasion. Fibrinolysis 1994;8 (suppl 1):189-203.

2 Del Rosso M, Fibbi G, Cerinic MM. The urokinase-type plasminogen activator system and inflammatory joint diseases. Clin Exp and inflammatory joint dise

3 Behrendt N, Stephens RW. The urokinase receptor. Fibrinolysis and Proteolysis 1998;12: 191-204.

4 Ronday HK, Smits HH, van Muijen GNP, Pruszzynski MSM, Dolhain RJEM, van Langelaan EJ, et al. Difference in expression of the plasminogen activation system in synovial tissue of patients with rheumatoid arthritis and osteoarthritis. Br J Rheumatol 1996;35:41623.

5 Stephens RW, Pedersen AN, Nielsen HJ, Hamers MJAG, Høyer-Hansen G, Rønne E, et al. ELISA determination of soluble urokinase receptor in blood from healthy donors and cancer patients. Clin Chem 1997;43:1876-84.

6 Slot O, Brünner N, Locht $\mathrm{H}$, Oxholm P, Stephens RW. Soluble urokinase plasminogen activator receptor in plasma of patients with inflammatory rheumatic disorders. Increased concentrations in rheumatoid arthritis. Ann Rheum Dis 1999;58:488-92.

\section{CORRECTION}

Epidemiology of whiplash (Barnsley L. Ann Rheum Dis 2000;59:394; Reply: Ferrari R, Russell AS. Ann Rheum Dis 2000;59:395-6.)

The Editor of the Annals regrets that we inadvertently published a reply to Dr Barnsley from Drs Ferrari and Russell that contained some misinformation, and offers his apologies to Dr Barnsley.

Possibly, Drs Ferrari and Russell were confusing Dr Barnsley with someone else. Firstly, Dr Barnsley is a man and not a woman, as they stated. Secondly, Dr Barnsley did not attend the World Whiplash Congress in Vancouver and has not read the transcripts of it and thus could not be, as Drs Ferrari and Russell commented, "well aware of an impressive study presented there".

(Note: Corrections printed in the journal also appear on the Annals web page (www. annrheumdis.com) and are linked to the original publication.) 